\title{
Combined stress myocardial perfusion and late gadolinium enhancement imaging by cardiac magnetic resonance provides robust prognostic information to cardiac events
}

\author{
Otavio Coelho-Filho ${ }^{*}$, François-Pierre Mongeon, Kevin Steel, Ron Blankstein, Damien Mandry, Bobby Heydari, \\ Michael Jerosch-Herold, Raymond Y Kwong
}

From 2011 SCMR/Euro CMR Joint Scientific Sessions

Nice, France. 3-6 February 2011

\section{Background}

Accurate non-invasive risk stratification may management and impact survival of CAD patients. Stress perfusion CMR reliably assesses ventricular function, viability and myocardial ischemia in a single examination. While prognostic information may be derived from individual components of a comprehensive CMR exam, evidence that they provide complementary prognostic information is still limited. We sought to determine whether the presence of myocardial ischemia by stress perfusion CMR provides incremental prognostic information for major adverse cardiovascular events (MACE) beyond ventricular function, the presence of myocardial scar and traditional risk factors in a large cohort of patients referred for non-invasive assessment of CAD.

\section{Methods and results}

Stress perfusion CMR was performed in 711 consecutive patients (297 females, mean age $56 \pm 15$ years) referred to assess myocardial ischemia with an intermediate pre-test likelihood of CAD (mean pre-test likelihood of CAD $22 \pm 18 \%$ ). Rest and vasodilator stress perfusion CMR were performed each using a $0.1 \mathrm{mmol} / \mathrm{Kg}$ bolus infusion of gadolinium, followed by cine function imaging and late gadolinium enhancement (LGE) 10 minutes after a cumulative dose of $0.2 \mathrm{mmol} / \mathrm{Kg}$ of gadolinium. The presence of myocardial ischemia was defined by a segmental stress-induced perfusion defect without matching segmental LGE. At a median follow-up of 21.4 months (range 2.5 months to 8.2 years), 52 MACE $(8 \%)$ had

Brigham and Women's, Boston, MA, USA occurred (29 cardiac deaths and 28 acute nonfatal MI). By univariable analysis, the presence of ischemia and LGE portended to $>11$-fold and $>3$-fold increases in MACE (LR $\chi 2,51.62$ and 17.02, both $\mathrm{P}<0.0001$, table1), respectively. Adjusting for age, LVEF, presence LGE and resting ST segment changes, presence of ischemia maintains a strong adjusted association with MACE (adjusted

Table 1 Univariable prognostic association with MACE

\begin{tabular}{|c|c|c|c|}
\hline Variable & $\mathrm{LR}_{\mathrm{x}} 2$ & HR & P-Value \\
\hline Age, per decade & 21.12 & $1 / 06$ & $<0.0001$ \\
\hline Gender & 0.05 & 0.94 & 0.8181 \\
\hline Hypertension & 13.62 & 3.51 & 0.0002 \\
\hline Diabetes & 13.17 & 2.80 & 0.0003 \\
\hline Hyperlipidemia & 9.75 & 2.90 & 0.0018 \\
\hline $\mathrm{Hx} \mathrm{MI}$ & $10 / 80$ & 2.58 & 0.0010 \\
\hline $\mathrm{Hx} \mathrm{PCl}$ & 11.60 & 2.71 & 0.0007 \\
\hline HX CABG & 3.95 & 2.08 & 0.0469 \\
\hline Pre-test Probability of CAD & 13.12 & 1.03 & 0.0003 \\
\hline Left bundle branch block & 2.59 & 2.01 & 0.1074 \\
\hline Significant Q Waves & 10.69 & 2.73 & 0.0011 \\
\hline Resting ST changes & 27.43 & 4.48 & $<0.0001$ \\
\hline Resting $T$ wave inversions & 10.73 & 2.57 & 0.0011 \\
\hline LVEF, per $10 \%$ & 25.94 & 0.96 & $<0.0001$ \\
\hline LVEDVi, per $10 \mathrm{ml} / \mathrm{m}^{2}$ & 13.54 & 1.01 & 0.0002 \\
\hline LVESVi, per $10 \mathrm{ml} / \mathrm{m}^{2}$ & 23.02 & 1.02 & $<0.0001$ \\
\hline Resting RWMA & 36.17 & 5.90 & $<0.0001$ \\
\hline Stress perfusion defect & 40.38 & 8.72 & $<0.0001$ \\
\hline Presence of LGE & 17.02 & 3.36 & $<0.0001$ \\
\hline ISCHEMIA presence & 51.62 & 11.53 & $<0.0001$ \\
\hline ISCH-SCORE & 84.06 & 1.19 & $<0.0001$ \\
\hline
\end{tabular}


Table 2 Best Overall model for MACE

\begin{tabular}{llll}
\hline Variable & $\mathbf{L R}_{\mathbf{X}} \mathbf{2}$ & P-value & Hazard Ratio \\
\hline ISCHEMIA presence & 14.44 & 0.0001 & 5.038 \\
ISCH-Score & 7.60 & 0.0058 & 1.097 \\
Resting ST changes & 16.56 & $<0.0001$ & 3.621 \\
\hline
\end{tabular}

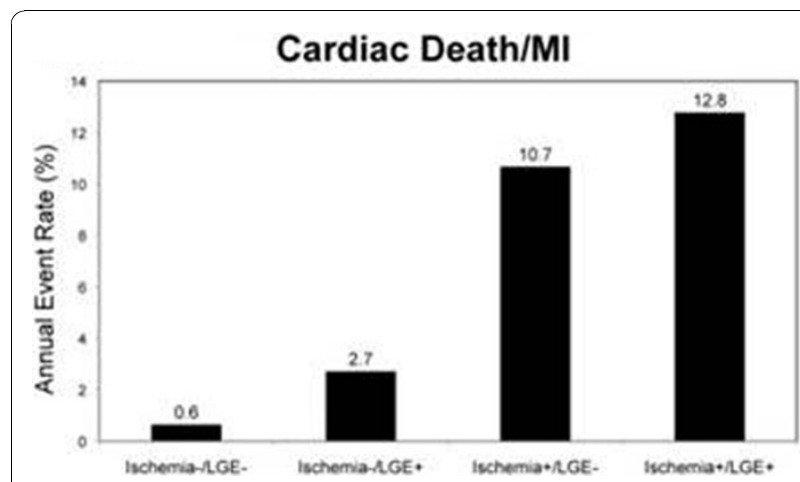

Figure 1 Cardiac Death/MI.

LR $\chi 2$ 26.1, HR 7.4, $\mathrm{P}<0.0001)$. By stepwise forward selection (table 2) considering all pertinent clinical, CMR and ECG variables, presence of ischemia remained the strongest predictor of MACE in the best-overall model. A stress perfusion CMR study without ischemia and LGE predicted a very low negative annual MACE rate $(0.6 \%$, figure 1$)$. In addition, the presence of ischemia was strongly associated with a reduced MACE-free survival (figure 2).

\section{Conclusion}

The presence of ischemia by stress perfusion CMR provides robust prognostic information for MACE beyond the presence of scar, LVEF, and classical clinical and ECG markers of cardiac prognosis. The combined absence of ischemia by myocardial perfusion imaging

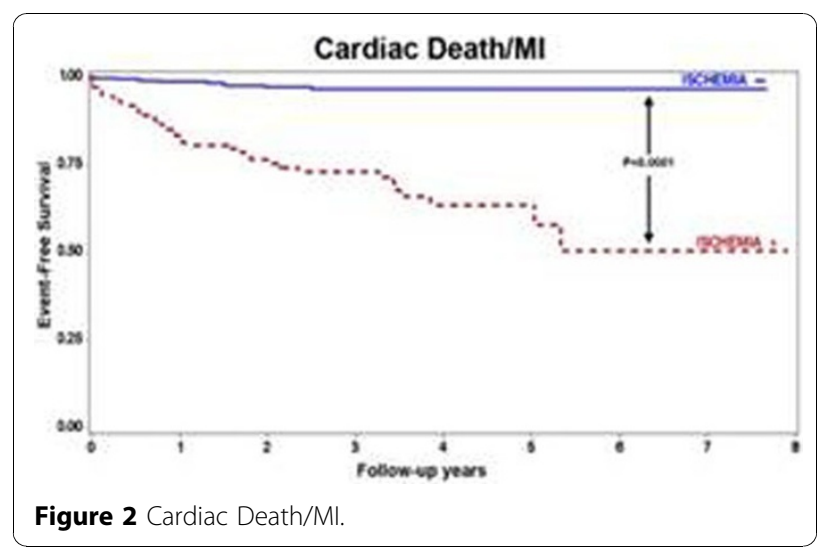

and scar by LGE imaging identifies a very low risk population.

Published: 2 February 2011

doi:10.1186/1532-429X-13-S1-O2

Cite this article as: Coelho-Filho et al:: Combined stress myocardial perfusion and late gadolinium enhancement imaging by cardiac

magnetic resonance provides robust prognostic information to cardiac events. Journal of Cardiovascular Magnetic Resonance 2011 13(Suppl 1):O2.

\section{Submit your next manuscript to BioMed Central and take full advantage of:}

- Convenient online submission

- Thorough peer review

- No space constraints or color figure charges

- Immediate publication on acceptance

- Inclusion in PubMed, CAS, Scopus and Google Scholar

- Research which is freely available for redistribution
C Biomed Central 